\title{
Hippocampal substrate of classical conditioning
}

\author{
R. F. THOMPSON, T. W. BERGER, S. D. BERRY, F. K. HOEHLER, \\ R. E. KETTNER, and D. J. WEISZ \\ University of California, Irvine, California 92717
}

\begin{abstract}
Results of a series of studies from our laboratory are reviewed which demonstrate that in simple associative conditioning paradigms there is a very early and marked increase in hippocampal neuron activity that precedes and predicts the development of behavioral learning, both over the trials of training and in terms of the actual amplitude-time course of the appropriate conditioned behavioral response being learned. Current approaches to the study of the possible behavioral functions of the hippocampus are examined, and current theories of hippocampal function are evaluated in the context of our experimental results.
\end{abstract}

Our approach to the hippocampus differs from that of many students of hippocampal function. We did not begin by asking, "What is the function of the hippocampus?" In our view, this question, as it is phrased, is not likely to be very meaningful. Brain structures do not exist in isolation. Indeed, they are only structures because we so name them. From a circuit analysis viewpoint, the brain is a set of synaptic interconnections with many specialized local features, some of which we name as structures. If the brain as a whole has any one function, it is information processing. Sensory stimulation is transduced, coded, "attended to," responded to, and compared against stored information, and its biological "significance" is evaluated and various response systems are activated. Whether or not a given brain "structure" like the hippocampus plays any particular or specialized role within this general framework can only be determined by very extensive empirical analysis. Even if it does, it seems very unlikely that a single phrase from the English language, such as "behavioral inhibition" or "spatial map," can serve adequately to characterize its functions.

Our basic interest is in neuronal substrates of learning. Modern analysis of brain mechanisms of learning and memory began with Pavlov's formulation of cortical representation (see Asratyan, 1980; Pavlov, 1927) and Lashley's concept of the localized memory trace or "engram" (see Lashley, 1929). A very large number of brain lesion studies of learning yielded negative results, in the sense that particular anatomically localized memory traces could not be demonstrated in the brain (see Lashley, 1950).

This outcome has forced most workers to abandon the notion of the localized engram; indeed, Lashley

Supported by research grants from NIMH (MH26530), NIH (NS 23368), NSF (BMS 75-00453), and the McKnight Foundation. This work was in process while the first author (RFT) was a fellow of the Center for Advanced Study in the Behavioral Sciences, Stanford, California, with the support of Center funds and funds from NIMH (5T 32 MH 14581-03) and NSF (BNS 76-22943 A02). had abandoned it by 1929 as a result of his own work. The logic underlying the notion of the localized engram seems to derive from an oversimplified conception of causality. It is an example of what the Soviet psychologist Boris Lomov (1980) has termed linear causality. The basic idea is a linear or series chain of events from stimulus inputs to final motor output, with a critical change developing at some point in the sequence in the brain. Hence, there would be a direct linear causal chain from this change, the engram, to the learned behavior. Except in very simple systems, it is doubtful if such elementary linear causality ever obtains in the central nervous system. In spite of this rather self-evident proposition, much lesion-behavior research still seems to adopt linear causality as a basic rationale.

Given that a localized engram does not exist and hence that brain mechanisms of learning cannot be accounted for in terms of linear causality, what are the alternatives? We wish to suggest that the memory system of higher animals-mammals-consists of a number of brain systems that play various roles during learning. These systems can be defined, or at least characterized, by anatomical and physiological criteria. Various systems may exist more or less separately, or may overlap or merge. They can have hierarchical organization (as in a sensory "system"), a partly temporal organization (as in certain motor systems), or alternative organizations that have not yet been characterized. The roles these various hypothetical brain systems play in learning and memory may or may not correspond to conceptual categories or terms that now exist. Note that such a multiple systems theory can also account for results of the lesion studies that give rise to Lashley's concepts of equipotentiality and mass action. A discrete lesion might interrupt only a part of one or more systems. They could still function, although perhaps not as well. A system, almost by definition, is not localized to one anatomical place. The larger the lesion, the more systems there are that are damaged, and the 
greater the damage is to some, yielding greater impairment.

In the Soviet Union, the systems approach to brain organization, particularly in the context of behavioral processes such as learning and motivation, is the dominant conceptualization. Pavlov's notion of the hierarchical organization of the brain has been developed extensively by modern workers in the Pavlovian tradition (e.g., Asratyan, 1980; Gasanov, 1980). A student of Pavlov, Peter Anokhin, has perhaps developed the systems approach most explicitly in his conception of goal-directed functional systems (1974). His students, in turn, have continued and extended this approach (e.g., Shvyrkov, 1980; Sudakov, 1965). A particularly clear example of the systems approach is to be found in Sokolov's analysis of the orienting response $(1958 / 1963)$.

Modern analysis of the human memory system in psychology provides a useful analogy. It is characterized as consisting of a number of systems with different properties which interact (see Atkinson \& Shiffrin, 1968). Sensory input is stored accurately but very briefly (up to $200 \mathrm{msec}$ ) in the sensory register or iconic memory (Sperling, 1960). It seems to be modality specific. Some of this information is transferred to longer term stores. The short-term memory store has a very limited capacity-about seven items or chunks of information (Miller, 1956) - decays over a period of about 10-12 sec (Petersen \& Petersen, 1959), and seems to involve recoding into "verbal", terms. The search through items in short-term store is linear, requiring about $37 \mathrm{msec}$ per item (Sternberg, 1966). Some information is established in long-term permanent store. The search process through longterm store is, of course, not linear. It takes less than $200 \mathrm{msec}$ to retrieve a remembered item, independent of the "size" of the item (Wickens, Note 1). However, once in short-term store, such items must be searched linearly. In addition to the several memory stores, there are a variety of control processes involved in storage and retrieval. Granted, this characterization of human memory is hypothetical and not accepted by all workers. Nonetheless, it has at least heuristic value and serves to illustrate, at a behavioral level, the notion of various systems playing various roles in learning and memory.

The literature on animal learning provides clear analogies to the human memory system. Consolidation, the well-established fact that a learning experience is fragile and easily manipulated for a short time after the experience (e.g., it can be impaired by ECS and anesthetics and facilitated; see Duncan, 1949; Hebb, 1955; Kety, 1976; McGaugh, 1966; McGaugh \& Herz, 1972), provides a close analogy to short-term memory. On the other hand, longterm memory can be prevented by substances that interfere with protein synthesis (Agranoff, 1967; Flexner, Flexner, \& Stellar, 1963). Wagner and asso- ciates have developed paradigms to analyze shortterm memory in rabbits (Terry \& Wagner, 1975). The human memory system seems, except for language, to be the mammalian memory system.

In our own work, we have utilized a "model system" approach to analysis of brain substrates of associative learning. In essence, this means the selection of a "prototypic" behavioral system, having the properties of associative learning, that is well defined and characterized and that exhibits robust learning. The model system approach has been employed very successfully for neural analysis of simple forms of behavioral plasticity such as habituation, in which reflexes of the neurally isolated spinal cord and reflex pathways in simpler invertebrates can be shown to exhibit the behavioral properties of habituation (Kandel, 1976; Thompson \& Glanzman, 1976). Since the ultimate goal of this field is an understanding of the brain substrates of human learning and memory, we felt constrained to develop a "model system" involving the intact mammalian brain.

We selected the preparation developed by Gormezano (Gormezano, Schneiderman, Deaux, \& Fuentes, 1962)-classical conditioning of the rabbit nictitating membrane (NM) response to a tone-conditioned stimulus (CS) using a corneal airpuff unconditioned stimulus (UCS) - as a simple and discrete model of mammalian learning. The rabbit NM system has a number of advantages for analysis of brain substrates of learning, which we have detailed elsewhere (Thompson, Berger, Cegavske, Patterson, Roemer, Teyler, \& Young, 1976; see also Disterhoft, Kwan, \& Lo, 1977). Some advantages are practical: the animal is held motionless but is not drugged or paralyzed, and significant learning occurs within a single 2 -h session; and some are conceptual: thanks to the extensive studies of Gormezano and associates (1972), the learned response is well characterized (it is an extremely well-behaved Pavlovian response and shows virtually no pseudoconditioning or sensitization), learning vs. performance substrates can be distinguished at the neuronal level, the actual amplitudetime course of the behavioral response can be measured easily and precisely, and the essential final common path controlling the response is relatively simple, involving only one cranial nerve (abducens).

Given the rationale developed above, we have adopted the general approach of recording neuronal unit activity during the course of learning in this preparation. The goal is to characterize the activity of various brain systems in learning and memory. Once this is accomplished, the structures and systems that exhibit altered activity with learning will have been identified and analysis of synaptic mechanisms will be feasible. We began by identifying the immediate neuronal substrate of the behavioral conditioned response-the motoneurons-and characterizing their activity during learning. Having defined the pat- 
tern of change of neuronal activity during learning at the final common path, it can be used as a neural "performance" measure against which to compare activity of higher brain structures and systems. All major brain systems must be explored. In view of the extensive earlier literature implicating the hippocampus in learning and memory (see e.g., Isaacson \& Pribram, 1975; Olds, Disterhoft, Segal, Kornblith, \& Hirsh, 1972; Scoville \& Milner, 1957; Sokolov, 1977; Sokolov \& Vinogradova, 1975; etc.), it seemed a reasonable place to begin.

\section{Methods}

The details of our procedures are given elsewhere and will be indicated only briefly here (Berger, Alger, \& Thompson, 1976; Berger \& Thompson, 1978a, 1978b, 1978c; Berry \& Thompson, 1978). We have adopted the behavioral procedures developed by Gormezano (1966). In our standard paradigm, animals are given a tone CS (1 kHz, $85 \mathrm{~dB}, 350 \mathrm{msec}$ duration) and a corneal airpuff UCS $(210 \mathrm{~g} / \mathrm{cm}$ pressure source, $100 \mathrm{msec}$ duration, occurring during the last $100 \mathrm{msec}$ of the tone CS-they terminate simultaneously). A mean intertrial interval of $60 \mathrm{sec}$ is used and varied from 50 to $70 \mathrm{sec}$ to eliminate possible temporal conditioning. Animals are given eight paired trials and one tone-alone test trial per block, and are typically given 13 such blocks in a day (i.e., training session). Unpaired control animals are given a pseudorandom sequence of unpaired CS and UCS presentations (explicitly unpaired procedure) with a mean interval of $30 \mathrm{sec}$ (varied from 20 to 40), for approximately the same total number of stimulus presentations per session as conditioning animals. The exact amplitude-time course of the NM extension response is measured by a micropotentiometer, recorded on tape, digitized at 3-msec intervals, and stored in the computer. Later analysis involves computation of onset latencies, averaged responses from eight trials, and measurement of the area under the NM response curve. This latter measure provides a useful index of the "amount" of the response in terms of both amplitude and time (Cegavske, Patterson, \& Thompson, 1979).

Unit spike discharges of neurons (either multiple-unit clusters or isolated single-unit potentials) are recorded using metal microelectrodes and stored on tape. The unit discharges are picked off by a discriminator, converted to standard pulses, and fed into the computer. The basic data collection program counts the number of unit discharges in each 3-msec time bin. Data collection begins 250 msec prior to tone CS onset (the pre-CS period) and continues through the $250 \mathrm{msec}$ of tone (the CS period) and then for an additional $250 \mathrm{msec}$ beginning with airpuff onset (the UCS period). Airpuff "onset" time is the time at which the airpuff actually arrives at the cornea. Unit counts are cumulated for display (e.g., in eight-paired-trial frequency histograms). The standard bin width used for display is $15 \mathrm{msec}$. Cumulated eight-trial unit count data are also converted to standard scores, relative to background (pre-CS) activity (e.g., for the CS period, the standard score is the mean CS counts minus the mean pre-CS counts divided by the standard error of the pre-CS activity, the latter computed on an entire day's session). The unit standard score measure for an eighttrial block for a given time period (e.g., the CS period or the UCS period) can be compared with the area under the averaged NM response curve for that same block of trials.

The multiple-unit microelectrode, of insulated stainless steel with a 5-7- $\mu$-diam tip and a 40-50- $\mu$ shaft exposed, is permanently implanted in the structure to be studied (while monitoring unit activity for localization), using halothane anesthesia. For singleunit recording, a small chronic microdrive system is implanted in the skull overlying the target structure, and single-unit microelectrodes-3-5- $\mu$-diam tip, insulated to the tip, $500 \mathrm{k} \Omega$ to $1 \mathrm{M} \Omega$ resistance-are inserted for each recording session. At least 1 week is allowed between surgical implantation procedures and the beginning of training-recording sessions.

Study of neuronal activity in the abducens motor nucleus provides both an example and a validation of our techniques. The highest correlation possible between neuronal and behavioral events should hold for the behavior and its immediate neuronal precedent, the activity of motoneurons in the final common path controlling the behavioral response. In initial studies, we identified the abducens (sixth nerve) motoneurons as the final common path for the NM extension response (NM extension is a largely passive consequence of eyeball retraction via the retractor bulbus muscle, innervated by the sixth nerve; Cegavske, Thompson, Patterson, \& Gormezano, 1976; Young, Cegavske, \& Thompson, 1976). We recently completed a study comparing eight paired conditioning and eight unpaired control animals with multiple-unit recording electrodes implanted in the abducens nucleus ipsilateral to the eye being conditioned (Cegavske et al., 1979). Examples of eight-trialaveraged NM responses and histograms of abducens unit activity are shown in Figure 1 for a conditioning animal before (A) and after (B) learning and for a control animal to airpuff (C) and to tone (D). Results are clear-there is a very close coupling between abducens unit activity and the behavioral response, independent of whether or not the animal has learned, whether it is a conditioning or control animal, and whether it is a conditioned response or a reflex response. Whatever the abducens neurons do, so does the nictitating membrane.

The group mean increases in neural and behavioral responses were compared over 2 days of acquisition training for the conditioning animals using index measures-the area under the NM response waveform and standard score of unit activity-for the CS period. For Day 1, the correlation coefficient between the neural and behavioral measures was .99 and for Day 2 it was .98 . There is thus a very close correlation between increases in the neural and behavioral measures across animals over the course of training, as might be expected when recording from the final common path for the behavioral response. These results provide good validation of the methods of recording and analysis used.

The close correspondence of the amplitude-time of the NM response and the histogram of unit activity from the motor nucleus (Figure 1) is extremely useful. It means that the easily recorded NM response actually portrays the temporal course of the histogram of unit activity in the motor nucleus. It is particularly helpful when studying changes in neuronal activity in higher brain structures during learning. It is necessary to compare the temporal patterns of neural activity in such structures against the pattern of activity in the final common path during acquisition of the conditioned response. Given the present findings (e.g., Figure 1), it is not necessary to record activity of abducens motoneurons during acquisition; measurement of the NM response form will suffice.

\section{The Hippocampal System}

Basic findings. Our current interest in the hippocampus stems from our initial observations of hippocampal neuronal activity during the course of classical conditioning of the rabbit NM response, made at Harvard in 1974 (Berger et al., 1976). The findingwhich was unexpected and, to us at least, in some ways extraordinary-is very simply that, in classical conditioning, neural activity in the hippocampus grows very rapidly to form a "temporal model" of the behavioral response being learned. This increased unit activity is highly predictive of behavioral learning over the trials of training and also highly predictive of the actual temporal morphology of the learned behavioral response within a trial (Berger et al., 1976; 
A

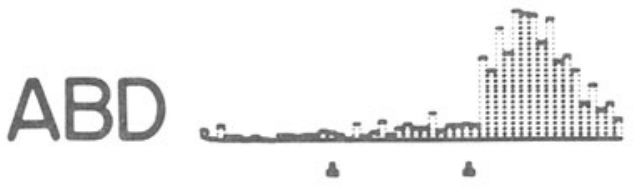

C
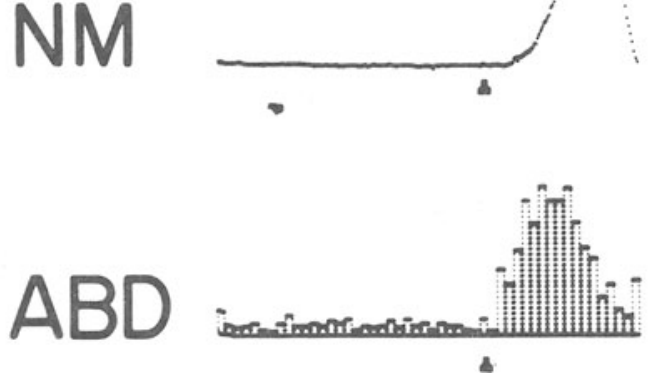
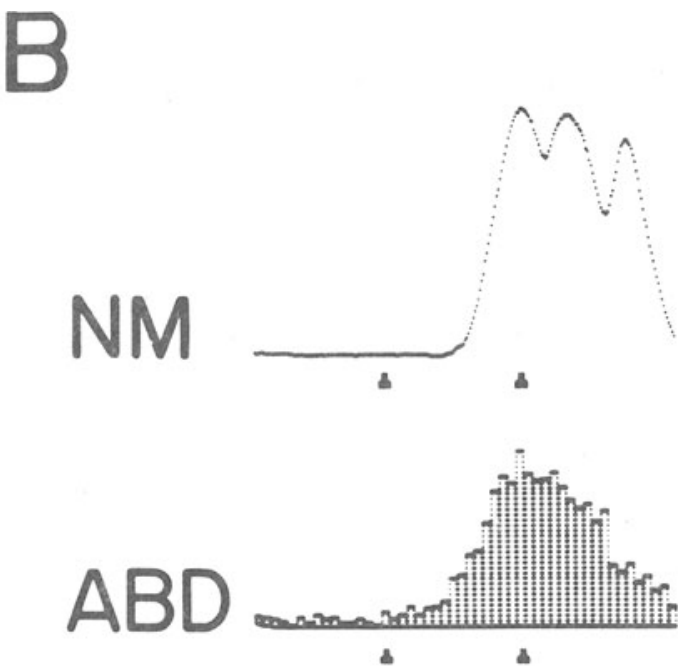

D

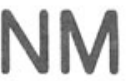

$\Delta$

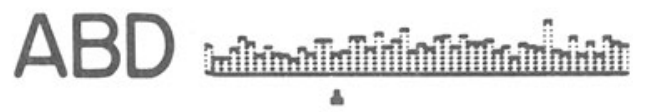

Figure 1. Examples of eight-trial-averaged behavioral nictitating membrane (NM) responses and associated multiple-unit histograms of abducens nucleus activity (15-msec time bins) for conditioning animals at the beginning and end of training (A, B) and a control animal for the airpuff $U C S(C)$ and the tone $C S(D)$. In this and all subsequent histogram figures, early cursor indicates tone onset, late cursor indicates airpuff onset. Total trace length equals 750 msec. Note the close correspondence between the histogram of unit activity and the behavioral NM response in all cases. (From Cegavske, Patterson, \& Thompson, 1979, reproduced by permission.)

Berger \& Thompson, 1978a; Berry \& Thompson, 1978; Thompson et al., 1976).

An example of the learned hippocampal unit response is shown in Figure 2. Note that the unit histogram shows a clear increase in the UCS period in the first block of eight paired trials (Figure 2A). Over training, this response increases markedly and moves into the CS period as behavioral learning develops. Indeed, Figures $2 \mathrm{~A}$ and $2 \mathrm{~B}$ closely resemble unit activity from the motor nucleus (see Figure 1). Ac- tually, the average latency of the hippocampal response is shorter than that for motoneurons $(42 \mathrm{msec}$ less than NM onset for hippocampal units and $17 \mathrm{msec}$ less than NM onset for motor units).

In marked contrast, the control animal hippocampal data are completely different from motoneuron activity. The eight-trial hippocampal unit activity and averaged NM are shown for airpuff-alone trials at the beginning and end of unpaired training for a control animal in Figures $2 \mathrm{C}$ and 2E. Although 


\section{PAIRED CONDITIONING}

A.

NM

CA 1

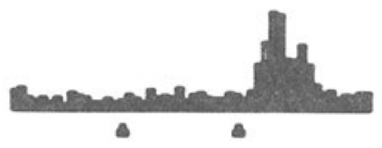

B.

NM

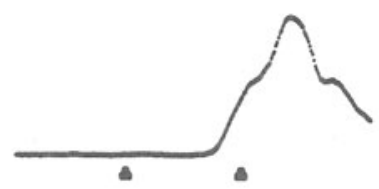

CA 1

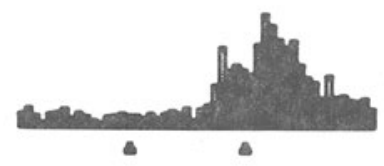

\section{UNPAIRED CONTROL}

C.

NM

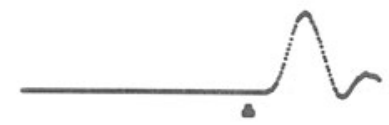

CA1

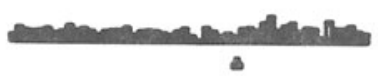

E.

NM

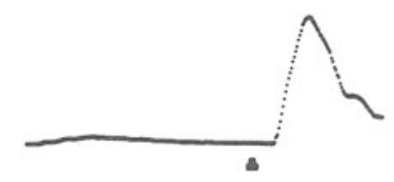

CA1

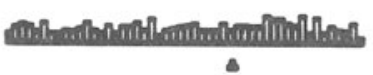

D.

\section{NM}

\section{CA 1}

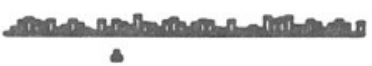

F.

NM

$\Delta$

\section{CA1}

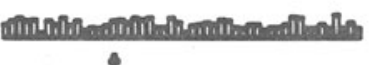

Figure 2. Examples of eight-trial-averaged behavioral NM responses and associated multiple-unit histograms of hippocampal activity for a conditioning (A, B) and a control (C-F) animal at the beginning and end of training. Note the very large increase in hippocampal unit activity that develops in the conditioning animal. Upper trace: Average nictitating membrane response for one block of eight trials. Lower trace: Hippocampal unit poststimulus histogram (15-msec time bins) for one block of eight trials. (A) First block of eight paired conditioning trials, Day 1. (B) Last block of eight paired conditioning trials, Day 1 , after conditioning has occurred. (C) First block of eight unpaired UCS-alone trials, Day 1. (D) Last block of eight unpaired UCS-alone trials, Day 2. (E) First block of eight unpaired CS-alone trials, Day 1. (F) Last block of eight unpaired CS-alone trials, Day 2. (From Berger \& Thompson, 1978a, reproduced by permission.) 
there is a clear reflex NM response, there is little associated unit activity in the hippocampus. There is essentially no NM response or evoked hippocampal activity in tone-alone trials (Figures $2 \mathrm{D}$ and $2 \mathrm{~F}$ ).

We completed an extensive study (Berger \& Thompson, 1978a) involving 21 conditioning animals and 12 unpaired controls, with multiple-unit recording in CA1-2 and CA3-4, given 2 days of training. The hippocampal unit responses illustrated in Figure 2 are closely paralleled for all animals in both conditioning and control groups. For both UCS and CS periods, unit activity in the hippocampus for conditioned animals increases and remains high over all 26 blocks of paired trials, reaching a mean standard score of about 15 in the UCS period and 7 in the CS period by the end of Day 2. In contrast, standard scores for animals given control training remain low (less than 3 standard scores for the UCS period and 1 standard score for the CS period) across blocks of unpaired trials.

Behavioral learning closely parallels the development of the hippocampal unit response in the CS period. For the average data, this occurred on about Block 6. On the average, behavioral conditioned responses began to occur when the hippocampal unit activity in the UCS period had increased to about 12-13 standard scores. This unit activity increases linearly over initial blocks of training and begins to decrease its rate of growth at about the time behavioral learning begins to occur.

A variety of control procedures (see Berger \& Thompson, 1978a) indicated that the hippocampal response is not a sensory evoked response per se, nor simply a motor concomitant of the behavioral NM response, but rather a result of paired conditioning training. However, as learning develops, the hippocampal unit response comes to resemble a "motor" response.

Because hippocampal unit activity appeared so highly developed at the end of the first block of paired trials in the UCS period (see Figure 2A), an individual trial analysis for the first eight paired trials was completed for all animals for the UCS period. A robust NM response to the airpuff was usually present from the first trial, yet the hippocampal unit response did not appear to develop in conditioned animals until later within the first block. An analysis of variance showed the paired-unpaired differences within the first block of training trials to be significant. Furthermore, the group data indicate no difference between groups on Trial 1 and then a growing separation between paired and unpaired groups beginning on Trial 2 (Berger \& Thompson, 1978a). Consequently, we suggested that this may be the first sign of the development of the engram in the brain (Thompson et al., 1976).

To determine the degree to which the temporal dis- tribution of increased hippocampal unit activity actually "models" and predicts the amplitude-time course of the behavioral NM response, we completed a correlation analysis on the 21 conditioning animals (Berger, Laham, \& Thompson, 1980). A correlation coefficient was computed for each trial block using the 3-msec values representing the averaged NM and the corresponding 3-msec values representing the cumulative hippocampal histogram for each animal and then averaged over all animals. As indicated in Figure 3, the hippocampal "model" grows from about $r=.32$ to $r=.63$ over the course of training. Because the hippocampal unit response precedes the $\mathrm{NM}$ response in real time by about $40 \mathrm{msec}$, we also completed a cross-correlation analysis, shifting the hippocampal unit response toward the NM response in $3-\mathrm{msec}$ increments. For a given block of trials, this correlation grows to reach a maximum value at the point of temporal synchrony between the two responses. The time difference between real time and the number of milliseconds of shift to yield the maximum correlation, incidentally, provides a very good estimate of the overall latency difference between the two responses (Berger, Laham, \& Thompson, 1980; Hoehler \& Thompson, 1980). This "maximized" correlation reaches a value of about $r=.82$ by the end of training. Thus, the pattern of increased firing of hippocampal neurons develops a very good predictive temporal "model" of the behavioral NM response.

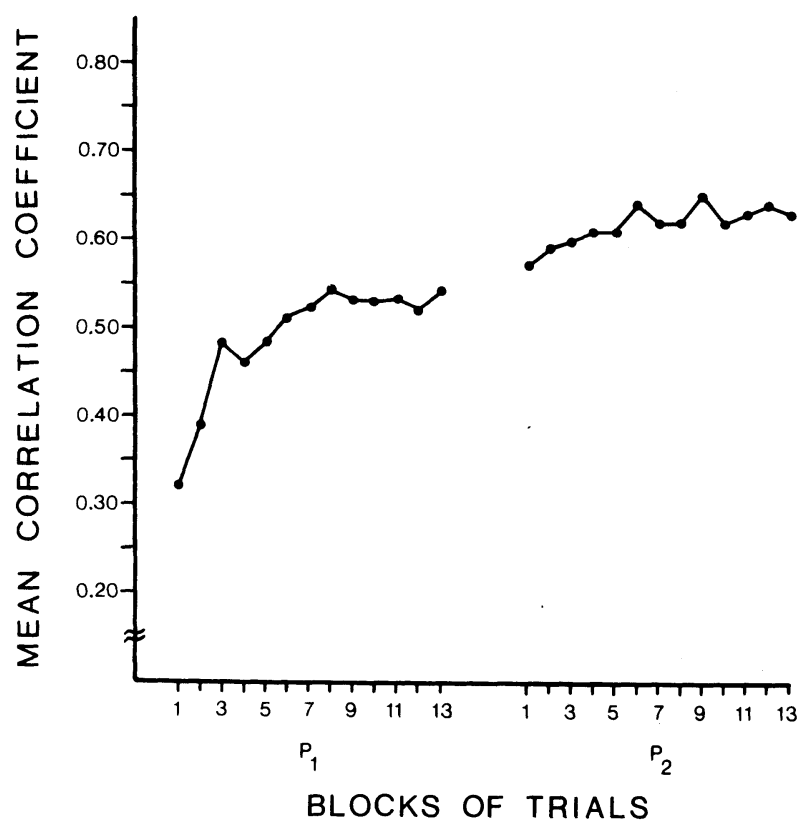

Figure 3. Graph of mean real-time correlation coefficient for 21 paired conditioning animals comparing the amplitude-time courses of the nictitating membrane response and the histogram of increased hippocampal neuron activity for each eight-trial block over the 2 days of training. (From Berger, Laham, \& Thompson, 1980, reproduced by permission.) 
Role of arousal. State of "arousal" is an important determinant of hippocampal activity (Bennett, 1975; Black, 1975; Lindsley \& Wilson, 1975; O'Keefe \& Nadel, 1978; see also O'Keefe, 1980; Ranck, 1975; Vanderwolf, Kramis, Gillespie, \& Bland, 1975). In particular, hippocampal "EEG" seems a useful index of behavioral arousal. Furthermore, the "state" of the hippocampal EEG is related to various aspects of hippocampal unit activity in a variety of mammalian species, including rabbit (see references cited just above and Berry, Rinaldi, Thompson, \& Verzeano, 1978; Lidsky, Levine, \& MacGregor, 1974). Perhaps the most extensive characterizations of hippocampal EEG in the context of behavioral "state" have been done with rat (O'Keefe \& Nadel, 1978; Vanderwolf et al., 1975; Winson, 1975). Rat and rabbit differ in that the awake rabbit, when motionless, tends to show good "theta," defined as low-frequency $(3-8 \mathrm{~Hz})$ synchronous EEG waves, whereas rat does not. Consequently, direct translations of EEG "state" from rat to rabbit are difficult. In any event, it is important for us to characterize possible relations between hippocampal EEG and unit activity in our rabbit NM conditioning paradigm.

In a series of studies (Berry et al., 1978; Berry \& Thompson, 1978, 1979), we have found clear interrelations among hippocampal EEG activity, hippocampal unit activity, and rate of learning. In brief, a 2-min time sample of hippocampal EEG taken prior to the onset of training is highly predictive of subsequent learning rate, even over a period of days, and also predictive of the rate of growth of conditioned increases in hippocampal unit activity. A higher proportion of hippocampal theta $(2-8 \mathrm{~Hz}$ in rabbit) predicts faster rates of learning $(r=+.72)$.

To our knowledge, this is among the few demonstrations that a purely neurophysiological measure taken prior to the beginning of training can predict the subsequent behavioral rate of learning. This result is nicely consistent with consolidation studies showing a positive relationship between amount of theta in the posttraining EEG and subsequent retention performance (Landfield, McGaugh, \& Tusa, 1972) and with studies reporting change in hippocampal EEG frequency and phase relations during training (Adey, 1966; Coleman \& Lindsley, 1977; Grastyan, Lissack, Madarasz, \& Donhoffer, 1959; Lindsley \& Wilson, 1975).

Prokasy (1972) has developed a most interesting mathematical model of behavioral learning for the rabbit classical conditioning NM paradigm, which indicates that learning occurs in two phases-an initial phase that extends from the beginning of training until the animal begins to give conditioned responses and a second phase that extends from this point until the response is well learned. Phase 1 is more variable and more likely to be influenced by "motivation," "arousal," and other conditions.
In part to determine if Prokasy's model could be extended to physiological measures, we compared the number of trials of training required to give the fifth conditioned response against the amount of change in the high/low EEG ratio over training for 16 conditioning animals. The result, shown in Figure 4, is striking and would seem to provide "physiological" substantiation of Prokasy's model. The correlation between the amount of change in the EEG ratio and the number of trials to the fifth $C R$ is $r=-.93$, a highly significant value. This result indicates that the greater the amount of change in the EEG in early training, the shorter the duration of Phase 1.

Lesions of the medial septum disrupt hippocampal theta (as has been shown in many studies) and also significantly retard both classical conditioning of the rabbit NM response and the growth of the conditioned increase in hippocampal unit activity (Berry \& Thompson, 1979). The impairment of learning appears to be due to a marked prolongation of Phase 1, again consistent with Prokasy's model.

It is clear from the above that rabbits come to our conditioning situation with a considerable range of "arousal states" as defined by hippocampal EEG. Furthermore, the rates of development of behavioral learning and the conditioned increase in hippocampal unit activity are related to hippocampal EEG. However, if the animal learns at all, the conditioned increase in unit activity invariably develops prior to the development of behavioral learning. That is to say, the conditioned increase in hippocampal unit activity does develop (in animals that learn behaviorally) over a wide range of hippocampal EEG states characteristic of the waking rabbit. The development of the

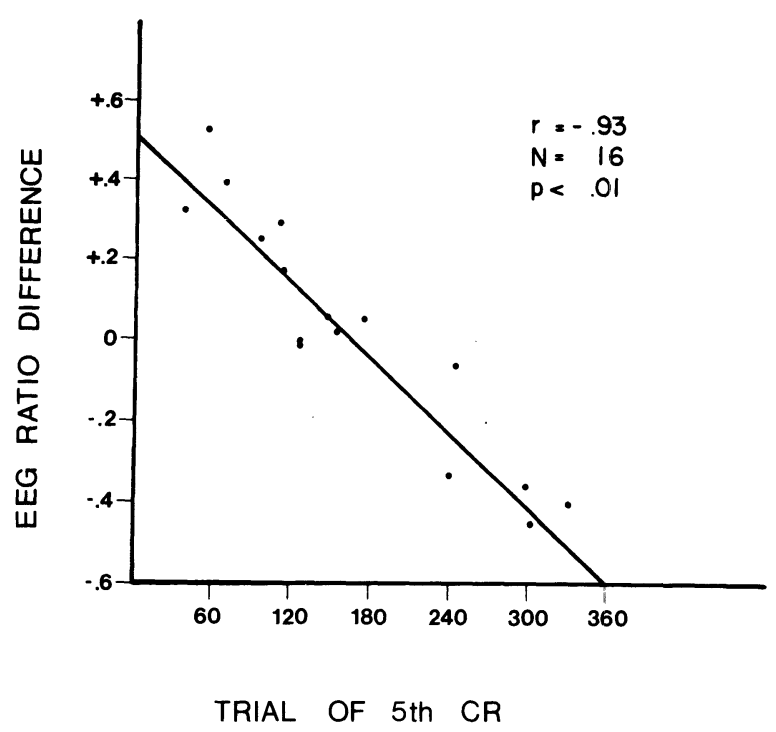

Figure 4. Scatterplot and regression line showing the relationship between the amount of change in the hippocampal EEG frequency ratio (see text) and the number of trials to the fifth conditioned response for a group of $\mathbf{1 6}$ paired conditioning animals. 
conditioned unit response is not dependent on hippocampal EEG "state," only its rate of development is. Once an animal has learned, the conditioned increase in hippocampal unit activity seems relatively permanent-it persists in animals trained and tested daily for periods as long as 1 month (Kettner \& Thompson, 1978).

Generality and relation to learning. Results described above suggest that the hippocampal system plays a very important role in simple learning in the normal, intact mammal. However, results described to date were all obtained under one standard set of conditions and stimuli. In order to determine the possible role(s) of the hippocampal system in learning and memory, it is necessary to explore the generality of the conditioned increase in hippocampal unit activity and to characterize its properties relative to behavioral learning. It must be noted that our general finding of a conditioned increase in hippocampal unit activity constitutes a clear verification and extension of the earlier work by Olds and Segal (e.g., Olds et al., 1972; Segal, 1973) and the work of Best (Best \& Best, 1976).

In a project concerned with signal detection, rabbits were overtrained and then given extensive threshold testing with simultaneous recording of neural unit activity from auditory relay nuclei and from the hippocampus (Kettner \& Thompson, 1978). Behavioral NM thresholds to the CS (white noise here) were about equivalent to human thresholds. Trials were separated into behavioral detection and nondetection. There was significant evoked unit activity in the cochlear nucleus, inferior colliculus, and medial geniculate on both detection and nondetection trials, and only very small differences between them. Hippocampal increased activity, in contrast, was fully developed on detection trials and nonexistent on nondetection trials (see Figure 5). The hippocampal response is thus independent of stimulus intensity. It is predictively coupled to the occurrence of the learned behavioral response. In signal detection terms, the "decision" to respond appears to occur after the auditory nuclei and at or before the hippocampus.

The rapid growth in hippocampal unit activity during paired conditioning training occurs in the same manner with a light CS as with a tone CS (Coates \& Thompson, 1978). It also occurs in the same manner in classical conditioning of the cat NM response (Patterson, Berger, \& Thompson, 1979). The phenomenon is thus independent of conditioned stimulus modality and is not species specific.

A critically important issue concerns the extent to which the conditioned increase in hippocampal unit activity is related to the learning aspect of behavior. As noted above, in the trained animal, the hippocampal response seems very much like a motor response that correlates closely with behavioral per-
A.

\section{COCHLEAR NUCLEUS}

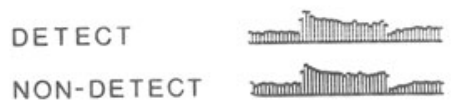

B.

INFERIOR COLLICULUS

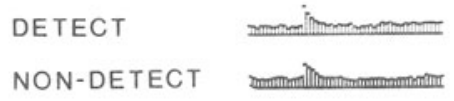

C.

MEDIAL GENICULATE

DETECT

NON-DETECT

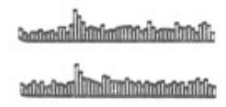

D.

HIPPOCAMPUS

DETECT

NON-DETECT

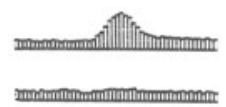

E.

BEHAVIOR

DETECT

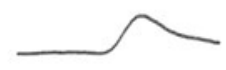

NON-DETECT

Figure 5. Comparison of multiple-unit responses from auditory relay nuclei and hippocampus during detect vs. nondetect trials. A through D: Average poststimulus histograms (15-msec time bins) created by averaging from 200 to 300 trials (obtained from several testing sessions) for cochlear nucleus (A), inferior colliculus (B), medial geniculate (C), and hippocampus (D) on detect (upper histogram) vs. nondetect (lower histogram) trials. E: Average nictitating membrane response for detect (upper trace) vs. nondetect (lower trace) trials. Detect trials were defined as trials in which at least $.5 \mathrm{~mm}$ of $\mathrm{NM}$ extension occurred within $500 \mathrm{msec}$ after CS onset on CS-alone trials. Note the large difference between hippocampal responses during detect vs. nondetect trials in comparison with the slight or nonexistent differences in responses of the auditory relay nuclei.

formance. Can the learning vs. performance aspect of the hippocampal response be distinguished? If it is related to learning, then variables that exert strong control over behavioral learning should have similar effects on hippocampal neural activity. The interstimulus interval (ISI), the time between CS and UCS onset, is a powerful determinant of conditionability in classical conditioning (Gormezano \& Moore, 1969). Gormezano and associates have completed an extensive parametric behavioral analysis of the ISI 
function for classical conditioning of the rabbit NM response (see Gormezano, 1972). They found no evidence of conditioning at backward, simultaneous, or 50-msec-forward pairings, some conditioning at $100 \mathrm{msec}$, maximal conditioning at $200-400 \mathrm{msec}$, and progressively poorer conditioning at longer intervals. Furthermore, the ISI strongly affects the topography or shape of the actual conditioned NM response-with the response peak always occurring near the point of UCS onset.

In a recent study (Hoehler \& Thompson, 1980), we recorded neural unit activity from the dorsal hippocampus (CA1) during the course of classical conditioning of the rabbit NM response to tone using three different ISIs: 50,150 , and $250 \mathrm{msec}$ (this last being the standard interval used in our previous studies). Results were strikingly clear and can be summarized in a simple sentence: The effect of the ISI on increased hippocampal unit activity is the same as its effect on the conditioned NM response. We submit that this is an extraordinary result. To our knowledge, it is among the few demonstrations of a brain event that correlates closely with the learning aspect of behavior and at the same time does not necessarily correlate with behavioral performance. Examples of the results are shown in Figures 6 and 7.

Data are summed over CS-alone test trials for the last half of Day 2 of training in Figure 6 (arrow indicates where airpuff would have occurred on paired trials). Any response of the NM or hippocampus would be a conditioned response, since no airpuff is given. For the standard 250-msec ISI (6A), both the conditioned NM response and the conditioned hippocampal activity are maximally developed, as described above. For the $150-\mathrm{msec}$ ISI (6B), the conditioned NM response form is narrower and the conditioned hippocampal unit response is similarly narrower and smaller. At the $50-\mathrm{msec}$ ISI $(6 \mathrm{C})$, there is no sign of behavioral learning or of increased hippocampal activity. Examples of data averaged over eight paired trials from Day 2 of training are shown in Figure 7. Results for conditioned increases in hippocampal unit activity are generally similar to the test trial data of Figure 6 for the 250- and 150-msec conditions. For the $50-\mathrm{msec}$ condition $(7 \mathrm{C})$, there is no increase in hippocampal unit activity, even though the closely paired tone-airpuff elicits a robust reflex NM response (which does not become conditioned-see Figure $6 \mathrm{C}$ ). This last result seems to us to provide an unambiguous dissociation between behavioral responding (i.e., performance) and increased hippocampal responding. In sum, whatever effects the stimulus and training conditions have on learning, they have the same effects on hippocampal unit activity. In other terms, the degree to which behavioral learning will occur can be predicted from the extent to which the hippocampal unit response develops.

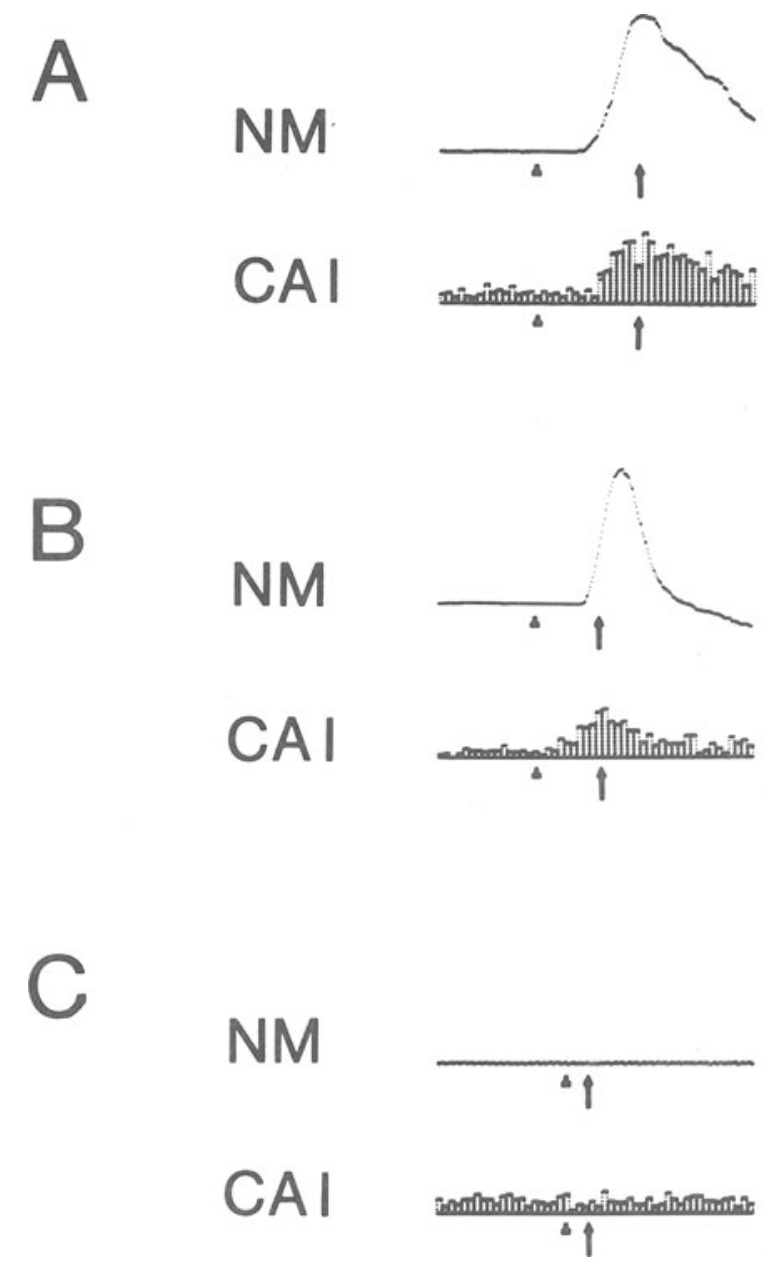

Figure 6. Averaged nictitating membrane responses (upper trace) and hippocampal poststimulus histograms (lower trace) from CS-alone test trials given during the last half of Day 2 (six trials). Data are from individual subjects trained with CS-UCS intervals of $250 \mathrm{msec}(\mathrm{A}), 150 \mathrm{msec}(\mathrm{B})$, and $50 \mathrm{msec}(\mathrm{C})$. Cursor indicates tone onset. Arrow indicates when the airpuff would have occurred on the paired trials. (From Hoehler \& Thompson, $1980 \mathrm{a}$, reproduced by permission.)

A critically important aspect of the generality of the hippocampal response relates to the NM paradigm. It would be odd if neurons in the hippocampus became massively engaged only in conditioning of the eyelid. In a preliminary study, we gave rabbits paired tone and hindlimb footshock, in the restraining apparatus, using the same temporal parameters as with the NM, except that animals were given only $50 \%$ reinforcement (random sequence) to permit recording during the UCS period on half the trials (Thompson, Land, Berger, \& Patterson, Note 2). Control animals were given explicitly unpaired stimuli. We recorded EMG activity from a hindlimb flexor muscle to provide a behavioral measure in some animals from each group. Hippocampal unit activity was recorded from dorsal CAl as in the NM studies above. Conditioned EMG activity exhibits an 


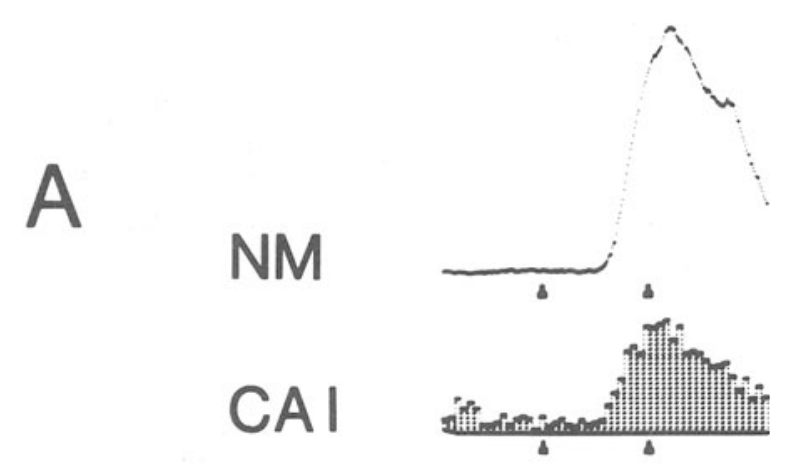

NM
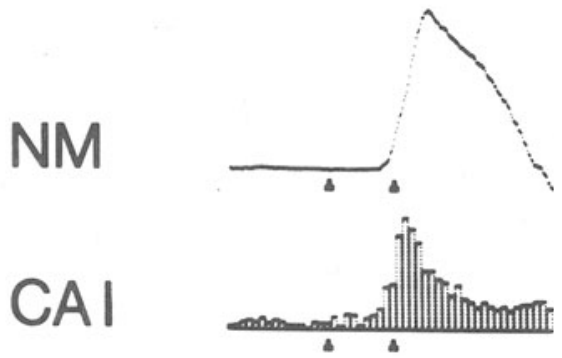

NM

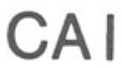

Figure 7. Averaged nictitating membrane responses (upper trace) and hippocampal unit poststimulus histograms (lower trace) from the last block of eight paired trials on Day 2. Data are from individual subjects trained with CS-UCS intervals of $250 \mathrm{msec}(A)$, $150 \mathrm{msec}(B)$, and $50 \mathrm{msec}(C)$. First cursor indicates tone. Second cursor indicates airpuff onset. (From Hoehler \& Thompson, 1980a, reproduced by permission.)

orderly acquisition in paired animals but no increases in unpaired controls. Although the Ns are too small to make strong statements, the conditioned EMG activity appears to develop substantially earlier in training than is the case for NM conditioning using corneal airpuff. Correspondingly, hippocampal unit activity shows an early, rapid, and significant increase in both the UCS and CS periods in the paired conditioning animals but not in the unpaired controls. Most important is the fact that the histogram of increased hippocampal unit activity precedes in time and appears to predict the temporal form of the conditioned increase in hindlimb EMG activity.

An example is shown in Figure 8 comparing an eight-trial histogram of hippocampal unit activity and a corresponding analysis of EMG spike activity for the same eight-trial block from a well-trained animal. Note that data were collected only on CSalone trials, so the increases are entirely due to conditioning. Comparable CS-alone test trial data for hippocampal units and the NM response in the NM conditioning paradigm are shown in Figure $6 \mathrm{~A}$ above. There are several points to be noted in Figure 8. First, as indicated above, the temporal pattern of the conditioned increase in hippocampal unit activity parallels closely the temporal pattern of conditioned increase in EMG activity. Second, the increase begins earlier in time for hippocampal unit activity than for the EMG. Third, and most important, is the fact that the temporal pattern of conditioned increases in hippocampal unit activity associated with conditioned EMG activity appears to differ from the pattern of conditioned hippocampal unit activity associated with the conditioned NM response (compare Figures $6 \mathrm{~A}$ and 8). The onset latencies are shorter in the EMG paradigm. Furthermore, both the conditioned increase in hippocampal unit activity and in the EMG activity tends to persist longer in time over the course of the trial period (again, compare Figures $6 \mathrm{~A}$ and 8). The $\mathrm{N}$ is at present small for the EMG paradigm, so our conclusion must be labeled preliminary. Nonetheless, the data of Figure 8, if considered representative, argue strongly that during learning, the hippocampus forms a temporal neuronal model of the appropriate behavioral response being learned, at least in classical conditioning paradigms involving an aversive UCS.

Since instrumental avoidance conditioning is in fact a classical training procedure until the occurrence of the first avoidance response, the conditioned increase in hippocampal unit activity we have described above undoubtedly develops in instrumental avoidance learning as well. Indeed, the behavioral paradigm initially developed by Olds and associates, in which they first found conditioned increases in hippocampal unit activity, involved both classical and instrumental components (Olds et al., 1972).

Mechanism. The experiments described above have all involved "multiple-unit" recording. Initial single-unit studies (Berger \& Thompson, 1978a) indicated that not all neurons in the hippocampus participate in the generation of the learned response. Indeed, using antidromic identification techniques, we determined that hippocampal pyramidal cells appear to be the neuronal elements that generate the learned response (Berger \& Thompson, 1978b). These results are described in detail in the paper by Berger, Clark, and Thompson (1980) in this symposium. Consistent with this finding is the fact that neural unit activity in the lateral septum, a major 

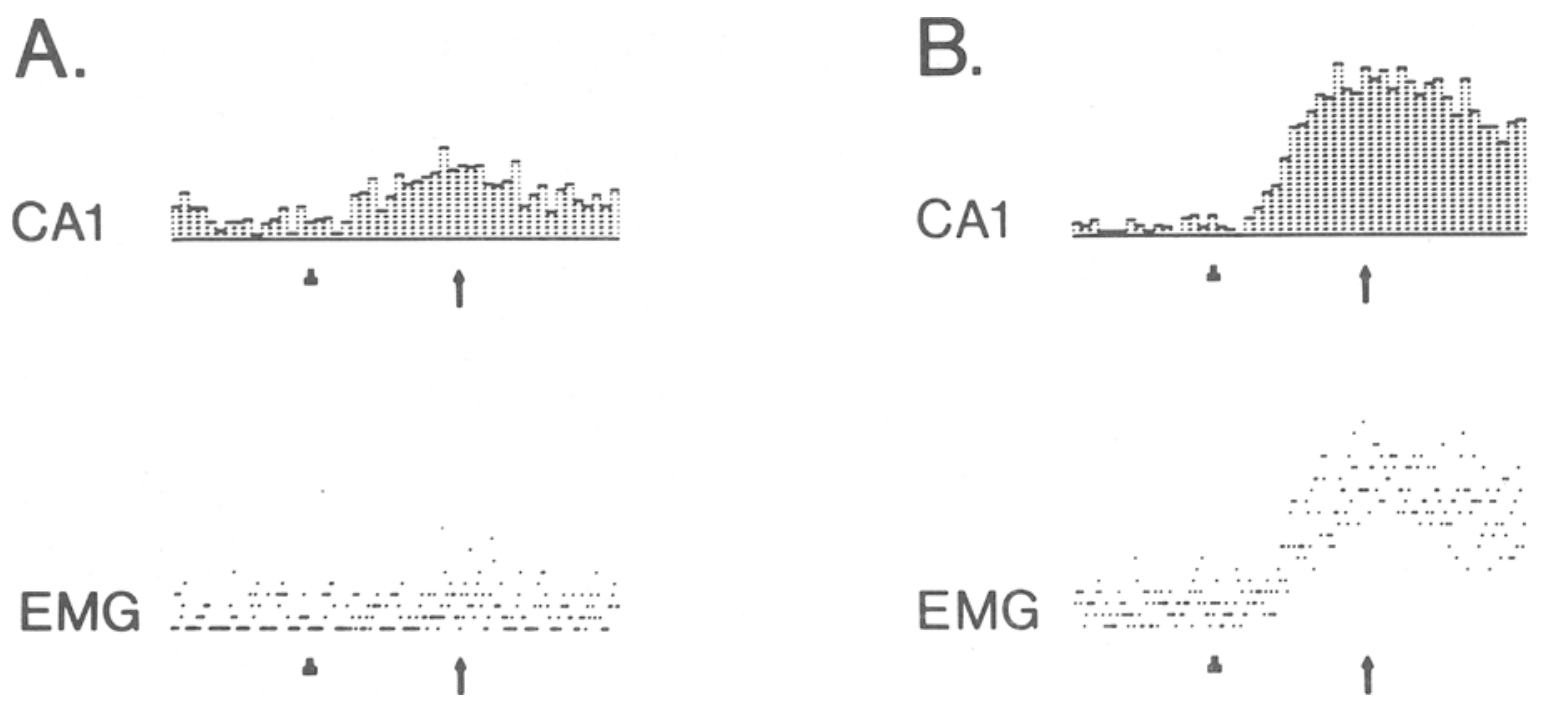

Figure 8. Poststimulus histograms summed over eight trial blocks for hippocampal unit activity summed in 3-msec time bins (CA1, upper traces) and hindlimb flexor muscle EMG activity (EMG, lower traces) in animals given paired tone-footshock training with a 50\% reinforcement schedule. Data recorded only on nonshock trials arrow indicate time when shock UCS onset would have occurred on paired trials. (From Thompson, Land, Berger, \& Patterson, Note 2.)

projection target of hippocampal pyramidal neurons, exhibits a similar conditioned increase which, interestingly, develops somewhat more slowly over trials than does the hippocampal response (Berger, Clark, \& Thompson, 1980; Berger \& Thompson, 1978c).

In order to analyze the synaptic mechanisms underlying the conditioned increase in hippocampal unit activity, it is necessary to: (1) identify the neurons generating the response (as we have donepyramidal neurons) and (2) demonstrate that the conditioned increase in fact occurs within the hippocampus. We have approached this second issue by simultaneous unit recordings from hippocampus and the major structures afferent to the hippocampus: the medial septum and the entorhinal cortex. Results are described in detail in Berger, Clark, and Thompson (1980). In brief, medial septal neurons show evoked activity to stimulus onsets but no conditioned increases over training (see also Berger \& Thompson, 1978c). Entorhinal unit activity does show a withintrial pattern of increased activity from the early stages of training; however, this activity does not appear to increase over the course of training (Berger, Clark, \& Thompson, 1980; Clark, Berger, \& Thompson, 1978). In short, although the initial pattern of increased unit activity in the hippocampus may be "projected" to it from entorhinal cortex, the growth in hippocampal unit activity over the course of training appears to develop within the hippocampus itself.

Thanks to the extensive basic knowledge available on the anatomy and physiology of the hippocampus, it is possible to test directly for long-term changes in excitability of various synaptic junctions. Specif- ically, the laminar analysis of field potentials in the hippocampus completed by Andersen, L $\phi \mathrm{mo}$, and associates (see, e.g., Andersen, 1975; L $\varnothing \mathrm{mo}, 1971$ ) makes it possible to record identified monosynaptic responses of hippocampal neurons to stimulation of fiber tracts. Winson and Abzug (1978) have recently made very good use of such field potential recording from the hippocampus of the waking animal in the context of the behavioral state.

In current work in progress, we are recording the monosynaptic population spike response of dentate granule cells to single-shock stimulation of the perforant path, interpolated $225 \mathrm{msec}$ after tone CS onset, over the course of classical conditioning in our rabbit NM paradigm. Preliminary results to date suggest that there is a progressive and prolonged increase in the population spike potential over the course of learning that correlates well with the development of behavioral learning (see Figure 9).

One of the most intriguing possible mechanisms that might form the basis of learning-dependent increases in hippocampal unit activity is the phenomenon of long-term potentiation (LTP). A relatively brief low-frequency tetanus $(10-15 \mathrm{~Hz})$ of perforant path (by electrical stimulation) leads to a persisting increase in excitability in dentate neurons (Andersen, 1975; Bliss \& Lømo, 1973; Douglas \& Goddard, 1975). LTP has been suggested as a possible synaptic mechanism underlying learning by several authors (e.g., Andersen, Sundberg, Sveen, \& Wigstrom, 1977; Berger \& Thompson, 1978a; Lynch, Dunwiddie, \& Gribkoff, 1977). However, there has been no direct evidence linking LTP with learning-induced increases in hippocampal unit activity. Our current finding 


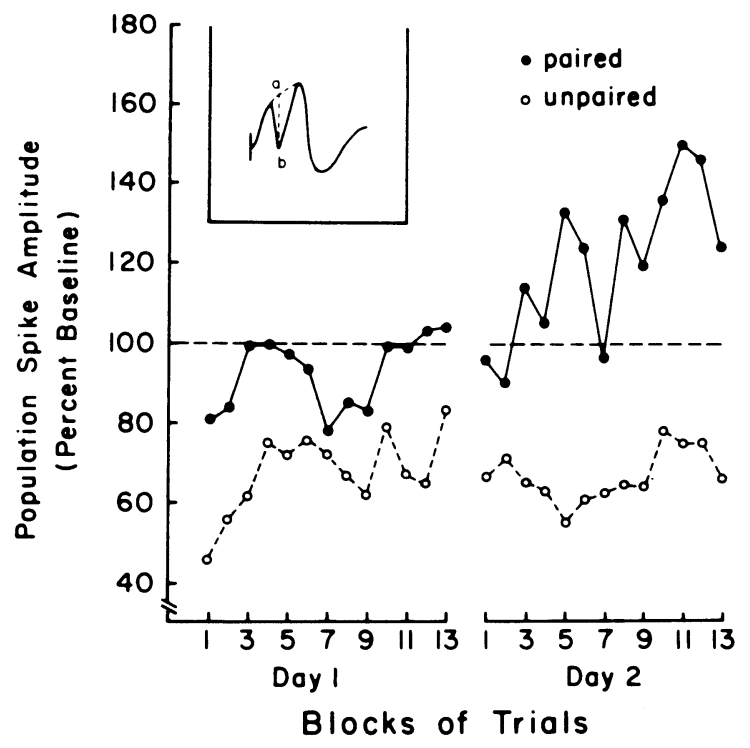

Figure 9. Average amplitude of the dentate granule cell population spike is plotted as a function of conditioning trials. The baseline amplitude (set at $100 \%$ ) was determined by averaging the amplitudes of 16 population spikes elicited immediately prior to the start of training on Day 1 . The inset depicts the measurement used for the amplitude determination. The distance from $A$ to $B$ was used as the spike amplitude. Individual responses were scored and training block averages were determined.

(Figure 9) is perhaps the first such evidence. It must, however, be considered tentative. If LTP in the perforant path to dentate granule cell synaptic junctions is in fact the mechanism of conditioned increases in hippocampal unit activity, several additional requirements must be met. First, it might be expected to occur in the intertrial interval as well as during the CS period. Second, it should also occur for the monosynaptic population EPSP response. Third, it must be shown that the increased excitability is not secondary to a conditioned increase in the afferent volley in the perforant path. Finally, it must be shown to be a homosynaptic increase in excitability (see Andersen, 1978). Evaluation of these possibilities is currently in progress in our laboratory.

\section{Discussion}

We do not have any particular theoretical axe to grind insofar as general theories of hippocampal function are concerned. As indicated earlier, it seems to us somewhat premature to develop a comprehensive theory of the "function" of the hippocampus, particularly in the face of our current ignorance. To take only one example, some basic neurobiological information is available about three types of neurons in the hippocampus-pyramidal cells, granule cells, and basket cells; yet, a recent review identified 21 morphologically distinct types of neurons in one region of the hippocampus (Amaral, 1978).

There are two methodological-theoretical issues that have assumed particular importance in the context of study of the hippocampus, both in this symposium and in the comprehensive volume by O'Keefe and Nadel (1978). One issue concerns the experimental approach. We have adopted a model system or "paradigmatic" approach to one aspect of behavior-learning. As noted above, this involves selection of a prototypic and simplified learning situation and then characterization of neuronal process in all relevant brain systems and structures. In the case of the hippocampus, having identified a learningdependent neuronal process, it is then necessary to determine the generality of the process in terms of stimulus and training variables, species, and other learning paradigms, and its relations to the "laws" or variables of learning. In the end, this approach will result in definition and analysis of the brain mechanisms of learning.

O'Keefe and Nadel (1978) approach the problem from the other end, using what they term a "neuroethological" strategy. In essence, they wish to determine the "function" of the hippocampus by study of the hippocampus, more or less in isolation, in a wide range of behavioral situations (see O'Keefe \& Nadel, 1978, pp. 190-196). A difficulty with the "neuroethological" approach is, of course, that neither the hippocampus nor any other brain structure exists in isolation. Another difficulty is the fact that their approach to behavior, in common with classical ethology, is basically observational. No time-locked simultaneous measurements of neural and behavioral events are made, nor is the fine structure of behavior measured. Our basic finding regarding the learningdependent neuronal process in the hippocampus described above would not have been possible without such measurements.

In the end, the relative merits of the "model system" vs. "neuroethological" approaches to brain and behavior will be determined empirically. At this point in time, we would simply note that in the classical conditioning paradigms we have used, neuronal activity in the hippocampus becomes massively engaged in a time-locked manner to the learned behavioral response-at least $80 \%$ of pyramidal neurons appear to become so engaged (Berger, Clark, \& Thompson, 1980; Berger \& Thompson, 1978b; Thompson \& Berger, 1979). Furthermore, as noted above, the pattern of increased frequency of hippocampal neuron discharge actually models the temporal fine structure of the learned behavioral response. In marked contrast, neuroethological studies of hippocampal neuron activity indicate only modest engagements in the behavioral observations and situations employed to date (O'Keefe \& Nadel, 1978; Ranck, $1973,1975,1978)$. This is not meant in any sense to deny the usefulness and importance of the extensive empirical studies of hippocampal unit activity in the freely moving animal by these authors and by others 
(e.g., Vinogradova, 1975). In particular, the observations of "spatial" units are most intriguing. We would, however, suggest that the ultimate interpretation of the significance of such unit responses must await a more fine-grained behavioral analysis.

The other issue concerns the logic of the lesion approach to brain substrates of behavior. O'Keefe and Nadel (1978, p. 194) imply that, because hippocampal lesions do not impair simple learning, the hippocampus plays no role in simple learning. This would seem to be an example of the "linear causality" argument. The motor systems of the mammalian brain provide a helpful analogy. There are a number of brain structures and systems categorized as "motor." They interact at all levels from the cerebral cortex to the final common paths. In animal studies, the effects of even large lesions of the motor structures and systems on motor behavior can range from severe, as with the cerebellum, to moderate or mild, as with the motor cortex and pyramidal tract, to virtually nondetectable, as with the basal ganglia. Yet, these systems are all characterized as motor. Even a motor structure as well developed in primates as the pyramidal tract can be ambiguous. Studies by Evarts (1964) show a precise coding of the force used in making hand and wrist movements by cells of origin of pyramidal tract fibers in the motor cortex of the monkey. Towe (1973), on the other hand, emphasizes the minimal nature of motor deficits by monkeys who have had complete bilateral section of the pyramidal tract. No one would argue from this absence of a lesion deficit that the pyramidal tract therefore plays no role in the control of movement. A particularly clear example concerns control of eye movements. In primate, two major control regions are the eye fields of the frontal cortex and the superior colliculus. However, there are essentially no deficits in eye-movement control following ablation of either region alone (Schiller, True, \& Conway, 1979). No one would conclude from this that the frontal eye fields or the superior colliculus are therefore not concerned with eye movements. Yet, many similar arguments are common regarding the roles of various brain structures in learning.

In general, the lesion-behavior approach per se has not been overly helpful in detailed analysis of the roles of brain structures in behavioral movement. Why, then, should we expect so much more from the lesion approach with regard to far more complex aspects of behavior such as learning and memory? Clearly, deficits in various learned behaviors following hippocampal lesions are of interest; indeed, there is a bewildering variety of such deficits. However, the absence of a deficit does not necessarily imply an absence of function.

In terms of classical conditioning of the rabbit NM response, lesions of the hippocampus do not prevent simple acquisition (Schmaltz \& Theios, 1972; Solomon
\& Moore, 1975). However, several more complex paradigms that use the classically conditioned rabbit NM response and involve the more remote aftereffects of stimuli (i.e., memory processes) do show profound impairment following hippocampal lesions: (1) the increasingly rapid extinction with repeated extinction sessions (Schmaltz \& Theios, 1972), (2) latent inhibition-the slowing of acquisition following CS-alone trials (Solomon \& Moore, 1975), and (3) the blocking of the response to the new element in a compound stimulus when the other element had previously been reinforced (Solomon, 1977). This literature is reviewed in detail by Solomon (1980b).

Lesions are not the only way to interfere with function; disruptive stimulation or activation has also provided a most useful tool (see Kesner, 1980). Although lesions of the hippocampus do not prevent simple classical conditioning of the rabbit NM response, disruptive electrical stimulation produces a profound impairment in this simple learning situation (Salafia, Romano, Tynan, \& Host, 1977), as does penicillin-induced hippocampal seizure activity (unpublished observations, our laboratory). Even small lesions to the medial septum that damage one projection system to the hippocampus produce marked impairment of simple acquisition of the NM conditioned response (Berry \& Thompson, 1979). As Isaacson (1974) noted, a malfunctioning hippocampus can be much worse than no hippocampus. These seemingly disparate results between lesions and disruptive activation of the hippocampus are entirely consistent with the "systems analysis" point of view described in the introduction and emphasize strongly that the hippocampus does not function in isolation.

In terms of current theories of hippocampal function, the results of our studies are generally consistent with those theories that implicate the hippocampus in learning and memory, particularly in relation to temporal and storage and/or retrieval processes (Adey, 1977; Douglas, 1967; Gabriel, Foster, Orona, Saltwick, \& Stanton, 1980; Hirsh, 1974, 1980; Isaacson, 1974; Jarrard, 1973; John, 1967; Kesner, Dixon, Pickett, \& Berman, 1975; Kimble, 1968; Livesey, 1975; Milner, 1970; Moore, 1979; Olds et al., 1972; Olton, Becker, \& Handelmann, 1979; Pribram, 1971; Routtenberg, 1972; Segal, 1973; Sokolov \& Vinogradova, 1975; Solomon, 1980a; Vinogradova, 1975).

Our results do not seem to be particularly consistent with the "spatial map" hypothesis of O'Keefe and Nadel (1978). However, it could be argued that in the classical conditioning situation, the conditioned stimulus becomes associated with contextual-spatial cues such as the restraining apparatus and the chamber (O'Keefe \& Nadel, Note 3). This still does not account for the fact that hippocampal neurons model the learned response. In any event, we planned a study in which there are no spatial-contextual cues- 


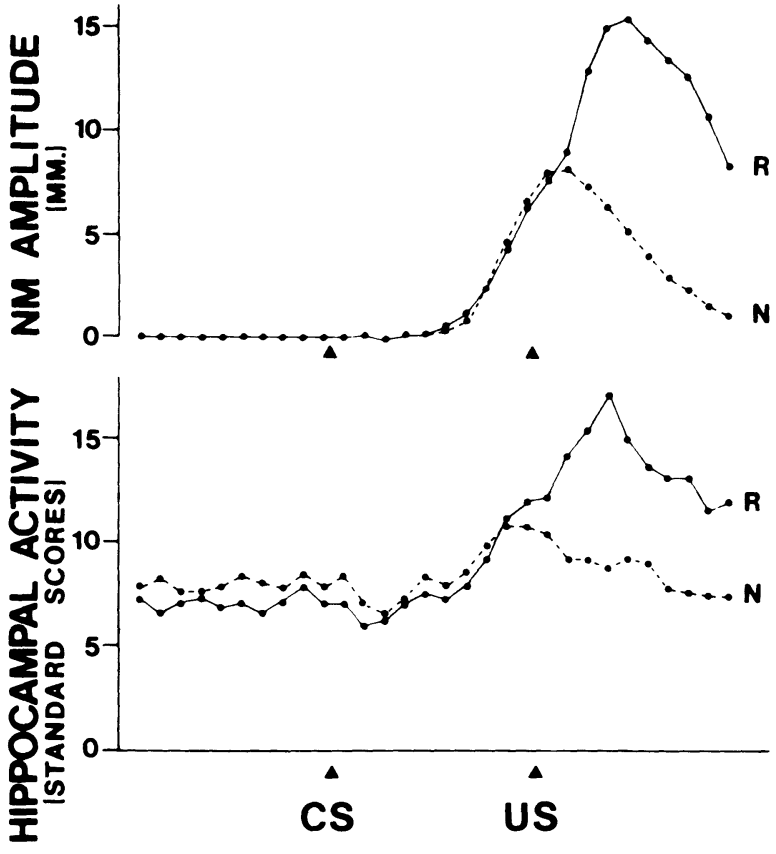

Figure 10. Mean NM topographies (upper graph) and mean increases in hippocampal neuron activity (lower graph) averaged over all animals and all trials of Day 3 of training, separately for reinforced $(R)$ and nonreinforced $(N)$ trials in a temporal singlealternation training paradigm. The conditioned NM response shows no effect of alternation training, but the conditioned increase in hippocampal neuron activity exhibits a highly significant effect in the last 10th of the CS period. (From Hoehler \& Thompson, 1979, reproduced by permission.)

temporal single alternation (Hoehler \& Thompson, 1979).

In brief, rabbits were given a strict alternation of reinforced $(\mathrm{R})$ and nonreinforced $(\mathrm{N})$ trials, using our standard conditions and procedures for classical conditioning of the NM response with multiple-unit recording from CA1 of the left dorsal hippocampus. Results are shown in Figure 10. In agreement with previous studies (Frey, 1969; Leonard \& Theios, 1967), the conditioned NM response does not itself exhibit temporal single-alternation patterning behavior (see Figure 10, upper). In other paradigms and/or response systems, the rabbit can produce learned temporal single-alternation behavior (e.g., Poulos, Sheafor, \& Gormezano, 1971), a finding that led us to this experiment. If the hippocampus is a part of a brain system involved in the coding of associative processes, then it ought to exhibit the associative aftereffects of the alternation schedule, even though the conditioned NM response does not. As we had hoped, hippocampal unit activity does show significant alternation prior to UCS onset (Figure 10, lower). There are actually two significant effects-a higher level of unit activity in the pre-CS period on nonreinforced trials and a higher level of unit activity in the last 10th of the CS period on rein- forced trials. (A separate control group ruled out possible nonassociative aftereffects of the stimuli.) In anthropomorphic terms, it is as though the hippocampus gradually "realizes" that a R trial is coming, but is unable to increase its activity sufficiently to influence differentially the NM response.

In a recent paper, Olton has reviewed the hippocampal lesion-behavior literature at length and concluded that damage to the hippocampus impairs all tasks involving "working" memory but not necessarily "reference" memory (Olton, Becker, \& Handelmann, 1979, 1980). He uses these terms as defined by Honig (1978), viz., in working memory tasks, stimulus information is useful for only one trial, whereas in reference memory, information is useful for many trials or the entire task. (A similar view of hippocampal function was proposed earlier by Douglas, 1967.) In the temporal single-alternation paradigm, the animal (in this case, the hippocampus) must make use of information from the stimulus events of the immediately preceding trial in order to respond correctly. Thus, it clearly involves working memory. Consequently, our result showing that conditioned hippocampal unit activity exhibits the temporal single-alternation effect would seem to be supportive of Olton's view. Our result is "strong" in the sense that the hippocampus exhibits the associative effects of alternation even though the learned behavioral NM response does not. In view of the fact that there are no conceivable differential spatialcontextual cues in the situation, our result would seem at variance with the "spatial map" hypothesis.

Our results are consistent with at least some aspects of "motor" theories of hippocampal function (e.g., Vanderwolf, 1971). Another way of describing the conditioned increase in hippocampal unit activity is as a learned motor program or motor plan. It is a very precise program of the amplitude-time course of the appropriate conditioned behavioral response being learned. Our results may provide an example in the hippocampus of what has variously been termed "efference copy" (von Holst, 1954), "corollary discharge" (Sperry, 1950), or "internal feedback" (Evarts, 1971). However, it occurs only for learned responses. It has some of the properties of what Sternberg, Mousell, Knoll, and Wright (1978) have termed a "motor buffer" for the retrieval of learned response sequences in humans.

To summarize our experimental results to date in the context of the possible role of the hippocampus in learning and memory processes, the marked increase in hippocampal unit activity that develops early and rapidly during classical conditioning with an aversive UCS is not dependent on CS intensity or modality, is not species specific, and is not specific to any one particular response system. Furthermore, this increase in hippocampal unit activity precedes and predicts the development of behavioral 
learning, both over the trials of training and in terms of the temporal morphology of the appropriate conditioned behavioral response being learned. Since instrumental avoidance conditioning is in fact a classical training procedure until the occurrence of the first avoidance response, the conditioned increase in hippocampal unit activity we have described undoubtedly develops in instrumental avoidance learning as well. Olds et al. (1972) and Segal (1973) earlier described increases in hippocampal unit activity in a mixed classical-instrumental learning situation involving food reward training. We therefore infer that the learning-dependent increase in hippocampal neuron activity that we have described is a general phenomenon whenever training involves the pairing of a signal stimulus and a reinforcing stimulus.

We suggest that the early developing conditioned increase in hippocampal unit activity is an electrophysiological representation of the "engram." Because this conditioned hippocampal activity grows rapidly to form a temporal model of the appropriate behavioral response being learned, we suggest further that the engram, wherever it may ultimately reside, is a motor plan-a stored "template" or temporal representation in the nervous system of the learned behavioral response to be made, at least in simple associative learning.

\section{REFERENCE NOTES}

1. Wickens, D. D. Personal communication, April 7, 1978.

2. Thompson, R. F., Land, T., Berger, T. W., \& Patterson, M. M. Learning induced increases in hippocampal neuron activity are a general phenomenon. Manuscript in preparation, 1980.

3. O'Keefe, J., \& Nadel, L. Personal communication, November $13,1979$.

\section{REFERENCES}

ADEY, W. R. Neurophysiological correlates of information transaction and storage in brain tissue. In E. Stellar \& J. M. Sprague (Eds.), Progress in physiological psychology (Vol. 1). New York: Academic Press, 1966.

ADEY, W. R. The sensorium and the modulation of cerebral states: Tonic environmental influences on limbic and related systems. In B. M. Wenzel \& H. P. Zeigler (Eds.), Tonic functions of sensory systems, Annals of the New York Academy of Sciences, 1977, 290, 396-420.

Agranoff, B. W. Agents that block memory. In G. C. Quarton, T. Melnechuck, \& F. O. Schmitt (Eds.), The neurosciences. New York: Rockefeller University Press, 1967.

Amaral, D. G. A Golgi study of cell types in the hilar region of the hippocampus in the rat. Journal of Comparative Neurology, 1978, 182, 851-914.

Andersen, P. Organization of hippocampal neurons and their interconnections. In R. L. Isaacson \& K. H. Pribram (Eds.), The hippocampus (Vol. 1). New York: Plenum Press, 1975.

Andersen, P. Long-lasting facilitation of synaptic transmission. In Functions of the septo-hippocampal system (Ciba Foundation Symposium 58, new series). Amsterdam: Elsevier, 1978.

Andersen, P., Sundberg, S. H., Sveen, O., \& Wigstrom, H. Specific long-lasting potentiation of synaptic transmission in hippocampal slices. Nature (London), 1977, 266, 736-737.

AnokHin, P. K. Biology and neurophysiology of the conditioned reflex and its role in adaptive behavior. New York: Pergamon
Press, 1974. (Russian ed. published by Meditsina, Moscow, 1968.)

Asratyan, E. A. Reflex mechanisms of motivated behavior. In R. F. Thompson, L. H. Hicks, \& V. B. Shvyrkov (Eds.), Neural mechanisms of goal-directed behavior and learning. New York: Academic Press, 1980 (in press).

Atrinson, R. C., \& Shiffrin, R. M. Human memory: A proposed system and its control processes. In K. W. Spence \& J. T. Spence (Eds.), The psychology of learning and motivation (Vol. 1). New York: Academic Press, 1968.

BennetT, T. L. The electrical activity of the hippocampus and processes of attention. In K. H. Pribram \& R. L. Isaacson (Eds.), The hippocampus (Vol. 2). New York: Plenum Press, 1975.

Berger, T. W., Alger, B. E., \& Thompson, R. F. Neuronal substrates of classical conditioning in the hippocampus. Science, 1976, 192, 483-485.

Berger, T. W., Clark, G. A., \& Thompson, R. F. Learningdependent neuronal responses recorded from limbic system brain structures during classical conditioning. Physiological Psychology, 1980, 8, 155-167.

Berger, T. W., Laham, R. I., \& Thompson, R. F. Hippocampal unit-behavior correlations during classical conditioning. Brain Research, 1980 (in press).

Berger, T. W., \& Thompson, R. F. Neuronal plasticity in the limbic system during classical conditioning of the rabbit nictitating membrane response. I. The hippocampus. Brain Research, 1978, 145, 323-346. (a)

Berger, T. W., \& Thompson, R. F. Identification of pyramidal cells as the critical elements in hippocampal neuronal plasticity during learning. Proceedings of the National Academy of Sciences, 1978, 75, 1572-1576. (b)

Berger, T. W., \& Thompson, R. F. Neuronal plasticity in the limbic system during classical conditioning of the rabbit nictitating membrane. II. Septum and mammillary bodies. Brain Research, 1978, 156, 293-314. (c)

Berry, S. D., Rinaldi, P. C., Thompson, R. F., \& Verzeano, M. Analysis of temporal relations among units and slow waves in rabbit hippocampus. Brain Research Bulletin, 1978, 3, 509-518.

Berry, S. D., \& Thompson, R. F. Prediction of learning rate from the hippocampal EEG. Science, 1978, 200, 1298-1300.

Berry, S. D., \& Thompson, R. F. Medial septal lesions retard classical conditioning of the nictitating membrane response in rabbits. Science, 1979, 205, 209-211.

Best, M. R., \& BEST, P. J. The effects of latent inhibition on hippocampal unit activity in the rat. Experimental Neurology, 1976, 51, 546-573.

BLACK, A. H. Hippocampal electrical activity and behavior. In R. L. Isaacson \& K. H. Pribram (Eds.), The hippocampus (Vol. 1). New York: Plenum Press, 1975.

Buiss, T. V. P., \& Løм0, T. Long-lasting potentiation of synaptic transmission in the dentate area of the anesthetized rabbit following stimulation of the perforant path. Journal of Physiology (London), 1973, 232, 331-356.

Cegavske, C. F., Patterson, M. M., \& Thompson, R. F. Neuronal unit activity in the abducens nucleus during classical conditioning of the nictitating membrane response in the rabbit, Oryctolagus cuniculus. Journal of Comparative and Physiological Psychology, 1979, 93, 595-609.

Cegavske, C. F., Thompson, R. F., Patterson, M. M., \& Gormezano, I. Mechanisms of efferent neuronal control of the reflex nictitating membrane response in the rabbit. Journal of Comparative and Physiological Psychology, 1976, 90, 411-423.

Clark, G. A., Berger, T. W., \& Thompson, R. F. The role of entorhinal cortex during classical conditioning: Evidence for entorhinal-dentate facilitation. Neuroscience Abstracts, 1978, 4, 673. (Abstract)

Coates, S. R., \& Thompson, R. F. Comparing neural plasticity in the hippocampus during classical conditioning of the rabbit 
nictitating membrane response to light and tone. Neuroscience Abstracts, 1978, 4, 806. (Abstract)

Coleman, J. R., \& Lindsley, D. B. Behavioral and hippocampal electrical changes during operant learning in cats and effects of stimulating two hypothalamic-hippocampal systems. Electroencephalography and Clinical Neurophysiology, 1977, 42, 309-331.

Disterhoft, J. F., Kwan, H. H., \& Lo, W. D. Nictitating membrane conditioning to tone in the immobilized albino rabbit. Brain Research, 1977, 137, 127-144.

Douglas, R. J. The hippocampus and behavior. Psychological Bulletin, 1967, 67, 416-442.

Douglas, R. M., \& GoddaRD, G. V. Long-term potentiation of the perforant path granule cell synapse in the rat hippocampus. Brain Research, 1975, 86, 205-215.

Duncan, C. P. The retroactive effect of electroshock on learning. Journal of Comparative and Physiological Psychology, 1949, 42, 34-44.

EvarTs, E. V. Temporal patterns of discharge of pyramidal tract neurons during sleep and waking in the monkey. Journal of Neurophysiology, 1964, 27, 152-171.

Evarts, E. V. Feedback and corollary discharge: A merging of the concepts. In E. V. Evarts, E. Bizzi, R. E. Burke, M. Delong, \& W. T. Thach (Eds.), Central control of movement. Neuroscience Research Progress Bulletin, 1971, 9, 86-112.

Flexner, J. B., Flexner, L. B., \& Stellar, E. Memory in mice as affected by intracerebral puromycin. Science, 1963, 141, 57-59.

FREY, P. W. Within- and between-sessions CS intensity performance effec:s in rabbit eyelid conditioning. Psychonomic Science, 1969, 17, 1-2.

Gabriel, M., Foster, K., Orona, E., Saltwick, S. E., \& Stanton, M. Neuronal activity of cingulate cortex, anteroventral thalamus and hippocampal formation in discriminative conditioning: Encoding and extraction of the significance of conditional stimuli. In A. N. Epstein \& J. M. Sprague (Eds.), Progress in psychobiology and physiological psychology (Vol. 1). New York: Academic Press, 1980.

Gasanov, U. G. The plasticity of interneuronal relations in learning. In R. F. Thompson, L. H. Hicks, \& V. B. Shvyrkov (Eds.), Neural mechanisms of goal-directed behavior and learning. New York: Academic Press, 1980 (in press).

Gormezano, I. Classical conditioning. In J. B. Sidowski (Ed.), Experimental methods and instrumentation in psychology. New York: McGraw-Hill, 1966.

Gormezano, I. Investigations of defense and reward conditioning in the rabbit. In A. H. Black \& W. F. Prokasy (Eds.), Classical conditioning II: Current research and theory. New York: Appleton-Century-Crofts, 1972.

Gormezano, I., \& Moore, J. W. Classical conditioning. In M. H. Marx (Ed.), Learning: Processes. London: Macmillan, 1969.

Gormezano, I., Schneiderman, N., Deaux, E., \& Fuentes, I. Nictitating membrane: Classical conditioning and extinction in the albino rabbit. Science, 1962, 138, 33-34.

Grastyan, E., Lissak, K., Madarasz, L., \& Donhoffer, H. Hippocampal electrical activity during the development of conditioned reflexes. Electroencephalography and Clinical Neurophysiology, 1959, 11, 409-430.

Heвв, D. O. Drives and the C.N.S. (conceptual nervous system). Psychological Review, 1955, 62, 243-354.

HiRSH, R. The hippocampus and contextual retrieval of information from memory: A theory. Behavioral Biology, 1974, 12, 421-444.

Hirsh, R. The hippocampus, conditional operations, and cognition. Physiological Psychology, 1980, 8, 175-182.

Hoe HLER, F. K., \& ThOMpson, R. F. Effect of the interstimulus (CS-UCS) interval on hippocampal unit activity during classical conditioning of the nictitating rabbit, Oryctolagus cuniculus.
Journal of Comparative and Physiological Psychology, 1980, 94, 201-215.

Hoenler, F. K., \& Thompson, R. F. The effect of temporal single-alternation on learned increases in hippocampal unit activity in classical conditioning of the rabbit nictitating membrane response. Physiological Psychology, 1979, 7, 345-351.

HonIG, W. K. Studies of working memory in the pigeon. In S. H. Hulse, W. K. Honig, \& H. Fowler (Eds.), Cognitive aspects of animal behavior. Hillsdale, N.J: Erlbaum, 1978.

IsaAcson, R. L. The limbic system. New York: Plenum Press, 1974.

Isaacson, R. L., \& Pribram, K. H. The hippocampus (Vols. 1 \& 2). New York: Plenum Press, 1975.

JARRARD, L. E. The hippocampus and motivation. Psychological Bulletin, 1973, 79, 1-12.

Jонn, E. R. Mechanisms of memory. New York: Academic Press, 1967.

KANDEL, E. R. The cellular basis of behavior. San Francisco: Freeman, 1976

KeSNER, R. P. An attribute analysis of memory. The role of the hippocampus. Physiological Psychology, 1980, 8, 189-197.

Kesner, R. P., Dixon, D. A., Pickett, D., \& Berman, R. F. Experimental animal model of transient global amnesia: Role of the hippocampus. Neuropsychologia, 1975, 13, 465-480.

KetTNER, R. E., \& Thом PSON, R. F. Neural correlates of a signal detection task in the rabbit. Journal of the Acoustical Society of America, 1978, 64, S137. (Abstract)

KETY, S. Biological concomitants of affective states and their possible role in memory processes. In M. R. Rosenzweig \& E. L. Bennett (Eds.), Neural mechanisms of learning and memory. Cambridge, Mass: M.I.T. Press, 1976.

Kimble, D. P. Hippocampus and internal inhibition. Psychological Bulletin, 1968, 70, 285-295.

Landfield, P. W., McGaugh, J. L., \& Tusa, R. J. Theta rhythm: A temporal correlate of memory storage processes in the rat. Science, $1972,175,87-89$.

LAShlEy, K. S. Brain mechanisms and intelligence. Chicago: University of Chicago Press, 1929.

LASHLEY, K. S. In search of the engram. Symposium of the Society for Experimental Biology (Vol. 4). New York: Cambridge University Press, 1950.

Leonard, D. W., \& Theios, J. Effect of CS-US interval shift on classical conditioning of the nictitating membrane in the rabbit. Journal of Comparative and Physiological Psychology, $1967,63,355-358$.

Lidsky, T. I., Levine, M. S., \& MacGregor, S. Hippocampal units during orienting and arousal in rabbits. Experimental Neurology, 1974, 44, 171-186.

Lindsley, D. B., \& Wilson, C. L. Brainstem-hypothalamic systems influencing hippocampal activity and behavior. In R. L. Isaacson \& K. H. Pribram (Eds.), The hippocampus (Vol. 2). New York: Plenum Press, 1975.

LivesEY, P. J. Fractionation of hippocampal function in learning. In R. L. Isaacson \& K. H. Pribram (Eds.), The hippocampus (Vol. 2). New York: Plenum Press, 1975.

Lфмо, T. Potentiation of monosynaptic EPSP's in the perforant path-dentate gradule cell synapse. Experimental Brain Research, 1971, 12, 46-63.

Lomov, B. F. Introductory remarks. In R. F. Thompson, L. H. Hicks, \& V. B. Shvyrkov (Eds.), Neural mechanisms of goaldirected behavior and learning. New York: Academic Press, 1980 (in press).

Lynch, G. S., Dunwiddie, T., \& Gribkoff, V. Specific longlasting potentiation of synaptic transmission in hippocampa slices. Nature, 1977, 266, 736-739.

McGAUGH, J. L. Time dependent processes in memory storage. Science, 1966, 153, 1351-1358.

McGaugh, J. L., \& Herz, M. J. Memory consolidation. San Francisco: Albion, 1972. 
Miller, G. A. The magic number seven plus or minus two: Some limits on our capacity for processing information. Psychological Review, 1956, 63, 81-97.

Milner, B. Memory and the medial temporal regions of the brain. In K. H. Pribram \& D. E. Broadbent (Eds.), Biological bases of memory. New York: Academic Press, 1970.

Moore, J. W. Brain processes and conditioning. In A. Dickinson \& R. A. Boakes (Eds.), Mechanisms of learning and memory: A memorial to Jerzy Konorski. Hillsdale, N.J: Erlbaum, 1979.

O'KeEFe, J., \& Conway, D. H. On the trail of the hippocampal engram. Physiological Psychology, 1980, 8, 229-238.

O'KeEFE, J., \& NADEL, L. The hippocampus as a cognitive map. New York: Oxford University Press, 1978.

Olds, J., Disterhoft, J. F., Segal, M., Kornblith, C. L., \& Hirsh, R. Learning centers of rat brain mapped by measuring latencies of conditioned unit responses. Journal of Neurophysiology, 1972, 35, 202-219.

Olton, D. S., Becker, J. T., \& Handelmann, G. E. Hippocampus, space and memory. The Behavioral and Brain Sciences, 1979, 2, 313-365.

Olton, D. S., Becker, J. T., \& Handelmann, G. E. Hippocampal function: Working memory or cognitive mapping? Physiological Psychology, 1980, 8, 239-246.

Patterson, M. M., Berger, T. W., \& Thompson, R. F. Neuronal plasticity recorded from cat hippocampus during classical conditioning. Brain Research, 1979, 163, 339-343.

Pavlov, I. Conditioned reflexes. New York: Oxford University Press, 1927.

Peterson, L. R., \& Peterson, M. J. Short-term retention of individual verbal items. Journal of Experimental Psychology, 1959, 58, 193-198.

Poulos, C. X., Sheafor, P. J., \& Gormezano, I. Classical appetitive conditioning of the rabbit's (Oryctolagus cuniculus) jaw movement response with a single-alternation schedule. Journal of Comparative and Physiological Psychology, 1971, 75, 231-238.

Pribram, K. H. Languages of the brain: Experimental paradoxes and principles in neuropsychology. Englewood Cliffs, N.J: Prentice-Hall, 1971.

Prokasy, W. F. Developments with the two-phase model applied to human eyelid conditioning. In A. H. Black \& W. F. Prokasy (Eds.), Classical conditioning II: Current research and theory. New York: Appleton-Century-Crofts, 1972.

RANCK, J. B., JR. Studies on single neurons in dorsal hippocampal formation and septum in unrestrained rats. I: Behavioral correlates and firing repertoires. Experimental Neurology, 1973, 41, 461-531.

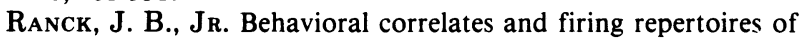
neurons in the dorsal hippocampal formation and septum of unrestrained rats. In R. L. Isaacson \& K. H. Pribram (Eds.), The hippocampus (Vol. 2). New York: Plenum Press, 1975.

RANCK, J. B., JR. Hippocampal units and theta activity (General Discussion II). In Functions of the septo-hippocampal system (Ciba Foundation Symposium 58, new series). Amsterdam: Elsevier/Excerpta Medica/North-Holland, 1978.

Routtenberg, A. Memory as input-output reciprocity: An integrative neurobiological theory. Annals of the New York Academy of Sciences, 1972, 193, 159-174.

Salafia, W. R., Romano, A. G., Tynan, T., \& Host, K. C. Disruption of rabbit (Oryctolagus cuniculus) nictitating membrane conditioning by postrial electrical stimulation of hippocampus. Physiology \& Behavior, 1977, 18, 207-212.

Schiller, P. H., True, S. D., \& Conway, J. L. Effects of frontal eye field and superior colliculus ablations on eye movements. Science, 1979, 206, 590-592.

Schmaltz, L. W., \& Theios, J. Acquisition and extinction of a classically conditioned response in hippocampectomized rabbits (Oryctolagus cuniculus). Journal of Comparative and Physiological Psychology, 1972, 79, 328-333.
Scoville, W. B., \& Milner, B. Loss of recent memory after bilateral hippocampal lesions. Journal of Neurology and Psychiatry, 1957, 20, 11-21.

Segal, M. Flow of conditioned responses in limbic telencephalic system of the rat. Journal of Neurophysiology, 1973, 36, 840-854.

Shvyrkov, V. B. Goal as a neuronal system-creating factor in behavior and learning. In R. F. Thompson, L. H. Hicks, \& V. B. Shvyrkov (Eds.), Neural mechanisms of goal-directed behavior and learning. New York: Academic Press, 1980 (in press).

Sokolov, E. N. Perception and the conditioned reflex (S. W. Waydenfeld, trans.). Oxford, England: Pergamon Press, 1963. (Originally published, 1958.)

SoKoLov, E. N. Brain functions: Neuronal mechanisms of learning and memory. Annual Review of Psychology, 1977, 28, 85-112.

Sokolov, E. N., \& Vinogradova, O. S. Neuronal mechanisms of the orienting reflex (N. M. Weinberger, English Ed.). Hillsdale, N.J: Erlbaum, 1975.

Solomon, P. R. The role of the dorsal hippocampus in blocking and conditioned inhibition of the rabbit's nictitating membrane response. Journal of Comparative and Physiological Psychology, 1977, 91, 407-417.

Solomon, P. R. Temporal versus spatial information processing theories of hippocampal function. Psychological Bulletin, 1980 (in press). (a)

Solomon, P. R. A time and a place for everything? Temporal processing views of hippocampal function with special reference to attention. Physiological Psychology, 1980, 8, 254-261. (b)

Solomon, P. R., \& Moore, J. W. Latent inhibition and stimulus generalization of the classically conditioned nictitating membrane response in rabbits (Oryctolagus cuniculus) following dorsal hippocampal ablations. Journal of Comparative and Physiological Psychology, 1975, 89, 1192-1203.

Sperling, G. The information available in brief visual presentations. Psychological Monographs: General and Applied, 1960, 74(Whole No. 496).

SPERRY, R. W. Neural basis of the spontaneous optokinetic response produced by visual inversion. Journal of Comparative and Physiological Psychology, 1950, 43, 482-489.

STERnbe RG, S. High speed scanning in human memory. Science, $1966,153,652-654$.

Sternberg, S., Mousell, S., Knoll, R. L., \& Wright, C. E. The latency and duration of rapid movement sequences: Comparisons of speech and typewriting. In G. E. Stelmach (Ed.), Information processing in motor control and learning. New York: Academic Press, 1978.

Sudakov, K. V. The interaction of the hypothalamus, midbrain reticular formation and thalamus in the mechanism of selective ascending cortical activation during physiological hunger. Fiziol. ah. SSR, 1965, 51, 449-456.

TerRY, W. S., \& WAgner, A. R. Short-term memory for "surprising" versus "expected" unconditioned stimuli in Pavlovian conditioning. Journal of Experimental Psychology, 1975, 104, 122-133.

Thompson, R. F., \& Berger, T. W. Responses of single hippocampal neurons during classical conditioning. Neuroscience Abstracts, 1979, 5, 325.

Thompson, R. F., Berger, T. W., Cegavske, C. F., Patterson, M. M., Roemer, R. A., Teyler, T. J., \& Young, R. A. The search for the engram. American Psychologist, 1976, 31, 209-227.

Thompson, R. F., \& Glanzman, D. G. Neural and behavioral mechanisms of habituation and sensitization. In R. N. Leaton \& T. J. Tighe (Eds.), Habituation: Perspectives from child development, animal behavior and neurophysiology. Hillsdale, N.J: Erlbaum, 1976.

Towe, A. L. Motor cortex and the pyramidal system. In J. D. Maser (Ed.), Efferent organization and the integration of 
behavior. New York: Academic Press, 1973.

VANDERWOLF, C. H. Limbic-diencephalic mechanisms of voluntary movement. Psychological Review, 1971, 78, 83-113.

Vande rwolf, C. H., Kramis, R., Gillespie, L. A., \& Bland, B. H. Hippocampal rhythmic slow activity: Relations to behavior. In R. L. Isaacson \& K. H. Pribram (Eds.), The hippocampus (Vol. 2). New York: Plenum Press, 1975.

VinogRadova, O. S. Functional organization of the limbic system in the process of registration of information: Facts and hypotheses. In R. L. Isaacson \& K. H. Pribram (Eds.), The hippocampus (Vol. 2). New York: Plenum Press, 1975.

von Holst, E. Relations between the central nervous system and the peripheral organs. British Journal of Animal Behaviour, 1954, 2, 89-94.

Winson, J. The mode of hippocampal function. In R. L. Isaacson \& K. H. Pribram (Eds.), The hippocampus (Vol. 2). New York: Plenum Press, 1975.

Winson, J., \& Abzug, C. Neuronal transmission through hippocampal pathways dependent on behavior. Journal of Neurophysiology, 1978, 41, 716-732.

Young, R. A., Cegavske, C. G., \& Thompson, R. F. Toneinduced changes in excitability of abducens motoneurons in the reflex path of the rabbit nictitating membrane response. Journal of Comparative and Physiological Psychology, 1976, 90, 424-434. 